\title{
A Modified Friction Stir Welding Process Based on Vortex Material Flow
}

\author{
Xiaochao Liu ${ }^{1,2,3^{*}}$, Y Yunqian Zhen ${ }^{1}$, Zhikang Shen ${ }^{1,2^{*}}$, Haiyan Chen ${ }^{1,2^{*}}$, Wenya Li ${ }^{1,2}$, Wei Guo ${ }^{1,2}$ \\ and Zhufeng Yue ${ }^{3}$
}

\begin{abstract}
Friction stir welding is a promising solid-state welding technique. However, the issue of tool wear and break restricts its wider industrial application. To avoid the tool wear and break occurring in conventional friction stir welding (FSW), a new modification of the FSW process using a tool made by the identical material as the workpiece has been developed and conducted on pure aluminum. We named this process as Vortex-FSW (VFSW) because it depends on a vortex material flow to realize the welding and joining. The weld macro- and micro-structures are like that in conventional FSW. However, the tool exit-hole in conventional FSW is replaced by a lug boss. The mechanical properties are also equivalent to that in conventional FSW. The principle of this new process is introduced in this paper.
\end{abstract}

Keywords: Friction stir welding, Tool materials, Vortex material flow, Viscous dissipation, Microstructure

\section{Introduction}

The current welding technologies based on friction generally utilize the friction between the workpieces (such as rotary friction welding, and linear friction welding) [1] or between workpiece and tool (such as friction stir welding) [2-5] to generate heat to soften the material and form plastic material flow. In this way, the original interface between the workpieces is broken to form an effective joint. For these welding technologies, owing to the limit of the processes' characteristics, the rotary friction welding and linear friction welding only can be used to weld the workpieces which have specific cross-section shapes. However, the two processes are nearly appropriate for all the materials which have thermal deformation capacity. FSW is a relatively new friction welding technology. Since it does not depend on the relative motion between the workpieces, FSW is suitable for various complex joint configurations, such as butt joint, lap joint, corner joint, T-type joint [6]. Shen et al. [7] recently reviewed the

\footnotetext{
*Correspondence: xcliu@nwpu.edu.cn; zhikangshen@nwpu.edu.cn; hychen@nwpu.edu.cn

${ }^{1}$ School of Materials Science and Engineering, Northwestern

Polytechnical University, Xi'an 710072, China

Full list of author information is available at the end of the article
}

advances in friction stir spot welding (FSSW), which is an important variant of FSW. In contrast with linear and rotary friction welding, FSSW also does not depend on the relative motion between the workpieces. However, no matter in FSW or FSSW, a rotating non-consumable tool is needed to insert into the workpiece for heat generation. Therefore, the strength, toughness, and wear resistance of the tool must be much higher than the base material (BM) [8]. This puts forward a very high demand for the tool materials.

Currently, FSW has been successfully applied in the industrial production of low-melting materials, such as aluminum alloys $[9,10]$, magnesium alloys [11, 12], copper alloys [13, 14]. Nevertheless, there is still a risk of tool breakage due to thermal fatigue when welding long distance. For the relatively high-softening-temperature materials, such as ferrous alloys, titanium alloys, nickel alloys, owing to that the tool is easily broken and worn, it is still difficult to industrialize the FSW. The countermeasures to these problems include developing new tool materials, designing new tool structures, optimizing welding parameters, etc. For example, Miyazawa et al. [15] developed an Ir based tool for friction stir welding of high-temperature materials. Wang et al. [16] found that the pin diameter is a key factor for the tool wear in 
FSW of Ti-6Al-4V alloy. The tool wear can be reduced by increasing the tool pin diameter. Sahlot et al. [17] reported the effect of process parameters on the wearinduced changes in the FSW tool pin profile. Through decreasing the tool rotating speed, the tool pin wear in length can be suppressed.

Recently, Liu et al. [18] reported that there exists a rotational flow zone around the tool in conventional FSW. The weld is formed by the material flow occurring out of the rotational flow zone. Liu et al. [19] further evaluated the strain and strain rate during the material flow occurring out of the rotational flow zone. The relationship between the strain/strain rate and the microstructure evolution was also revealed subsequently [20,21]. In this paper, inspired by the material flow and microstructure evolution in conventional FSW and the advantage of traditional friction welding processes, we put forward a new concept of the FSW process, in which the tool is made by the identical material as the BM.

As shown in Figure 1, the tool consists of a holder and a stir bar. The stir bar has identical material with the BM. In welding, the tool is rotated and pressured onto the workpiece top surface. The generated heat due to the friction between the stir bar and the workpiece and the following viscous dissipation softens the material, and thus a vortex material flow forms beneath the tool. When the tool moves along the joint line, the vortex material flow also moves together with the tool. In this way, the original interface between the workpieces will be broken to form a sound joint.

Figure 2 shows the four stages of this new welding process. Firstly, the stir bar needs to be driven to a certain rotation speed by the holder. Also, the end of the stir bar should be outer of the holder. Secondly, the stir bar together with the holder is pressured toward the workpiece, during which the stir bar is welded together with the workpiece, just like the conventional friction welding. As the holder is pressured toward the workpiece,

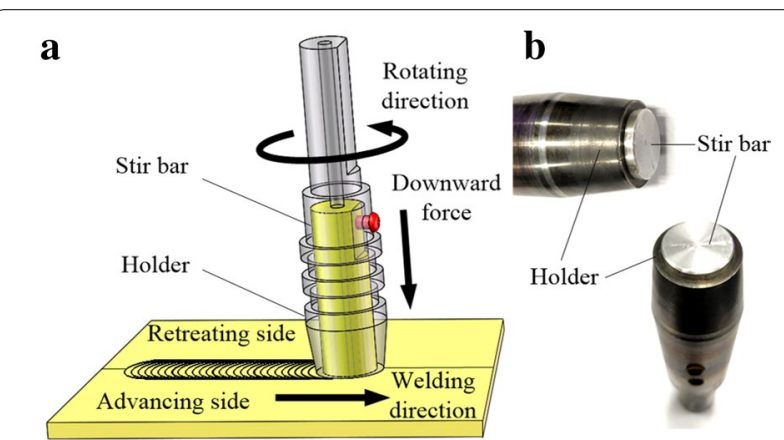

Figure 1 Schematic of the experiment: a schematic of the Vortex-FSW; $\mathbf{b}$ holder and stir bar used in the current experiment

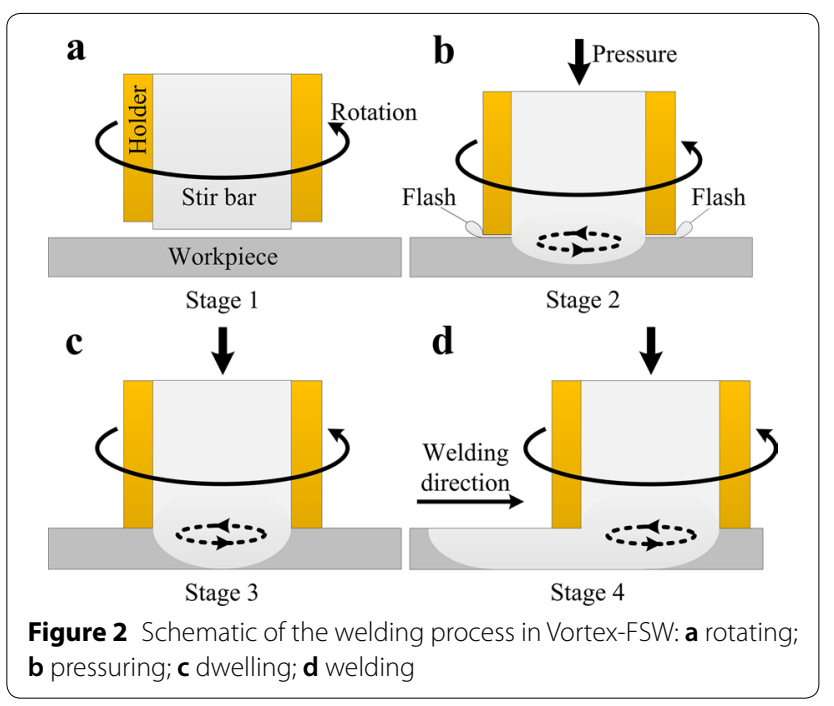

the redundant material between the stir bar and the workpiece will overflow and form flashes. Due to the weld between the identical materials (the stir bar and the workpiece), the material in the workpiece is also driven to rotating motion by the holder. Thirdly, as the holder feeds, the rotating flow zone enlarges to a constant volume. The vortex material flow reaches a quasi-steadystate. Fourthly, the holder moves in the welding direction, and accordingly, the vortex material flow moves together with the holder. A sound weld is formed after the holder passes.

Theoretically, this new FSW process can be used to weld all the materials which have thermal plastic deformation capacity and it does not care about the tool materials. Due to the key factor of this new FSW process is the vortex material flow, we named this new process as Vortex-FSW (VFSW). The potential disadvantages might be that the weld penetration is limited and the holder touching the workpiece may be worn. However, the load suffered by the end of the holder should be much lower than that suffered by the tool in conventional FSW, because most of the welding load is suffered by the stir bar. Therefore, the wear of the holder in VFSW should be slighter than the wear of the tool in conventional FSW.

\section{Experimental Section}

We conducted the VFSW on pure aluminum to verify the feasibility of this new process. The BM used in this experiment were cold-rolled commercial pure aluminum AA1050-H24 sheets with a thickness of $3 \mathrm{~mm}$. The stir bar was an AA1050-H24 aluminum bar with a diameter of $16 \mathrm{~mm}$. The holder was made by tool steel H13. The wall thickness of the holder end was $2 \mathrm{~mm}$, as shown in Figure 1b. The welding speed used in this study was 
constant and $30 \mathrm{~mm} / \mathrm{min}$. The rotating speed of the tool ranges from $200 \mathrm{r} / \mathrm{min}$ to $400 \mathrm{r} / \mathrm{min}$. The tool axis was perpendicular to the workpiece top surface. The FSW machine worked in a displacement control mode, guaranteeing the holder end touching the workpiece top surface closely. After welding, the weld transverse crosssection and the weld end longitudinal cross-section were prepared for the observation of the weld macro- and microstructures. The optical microscope and electron back-scattered diffraction (EBSD) technique were used to characterize the macro- and microstructures, respectively. The metallographic specimens were first prepared by mechanical polishing and 5\% HF etching. For the EBSD measurement, the specimens were electrolytically polished at $20 \mathrm{~V}$ and $0{ }^{\circ} \mathrm{C}$ in a solution of $10 \%$ $\mathrm{HClO}_{4}+90 \% \mathrm{C}_{2} \mathrm{H}_{5} \mathrm{OH}$ by volume. A ZEISS SUPRA fieldemission scanning electron microscope with the Channel 5 system was used. The scanning step size was $0.5 \mu \mathrm{m}$. The low-angle boundary (LAB) and high-angle boundary $(\mathrm{HAB})$ were distinguished by misorientation angle $2-15^{\circ}$ and $>15^{\circ}$, respectively. The grains were identified by a continuous boundary (misorientation angle $>2^{\circ}$ ) in the EBSD maps. The grain size was quantified in the Channel 5 system, which was calculated by each grain area and the circle equivalent diameter.

The joint mechanical properties were evaluated by the Vickers hardness test with a DHV-1000Z testing machine. The used load and dwell time were $100 \mathrm{~g}$ and 15 $\mathrm{s}$, respectively. The microhardness of the weld transverse cross-sections was measured on a grid of spacing $500 \mu \mathrm{m}$ in the horizontal and vertical directions. Then, 2D microhardness distribution maps were performed.

\section{Results and Discussion}

Figure 3 shows the typical weld morphology, which was obtained at $300 \mathrm{r} / \mathrm{min}$. Figure $3 \mathrm{a}$ and $\mathrm{b}$ show the top and bottom surfaces of the weld, respectively. There is no obvious external defect. The weld width on the bottom surface is similar to that on the top surface. At the end of the weld, a lug boss takes the place of the keyhole which inherently exists in the conventional FSW [6]. Figure 3c shows the close-up of the lug boss at the end of the weld. It was formed by the rotating stir bar when the tool exited from the workpiece. The stir bar before and after welding is shown in Figure 3d. It can be seen that the stir bar has been distortional severely after welding. The deformation has spread from the end of the stir bar to the clamped position. Therefore, the stir bar in VFSW is a consumable part. Nevertheless, owing to that the material of the stir bar is identical with the BM, the cost of the stir bar is very low. Especially for the high-softening-temperature materials, if the VFSW could replace the conventional FSW, the cost of the tool will be reduced greatly.
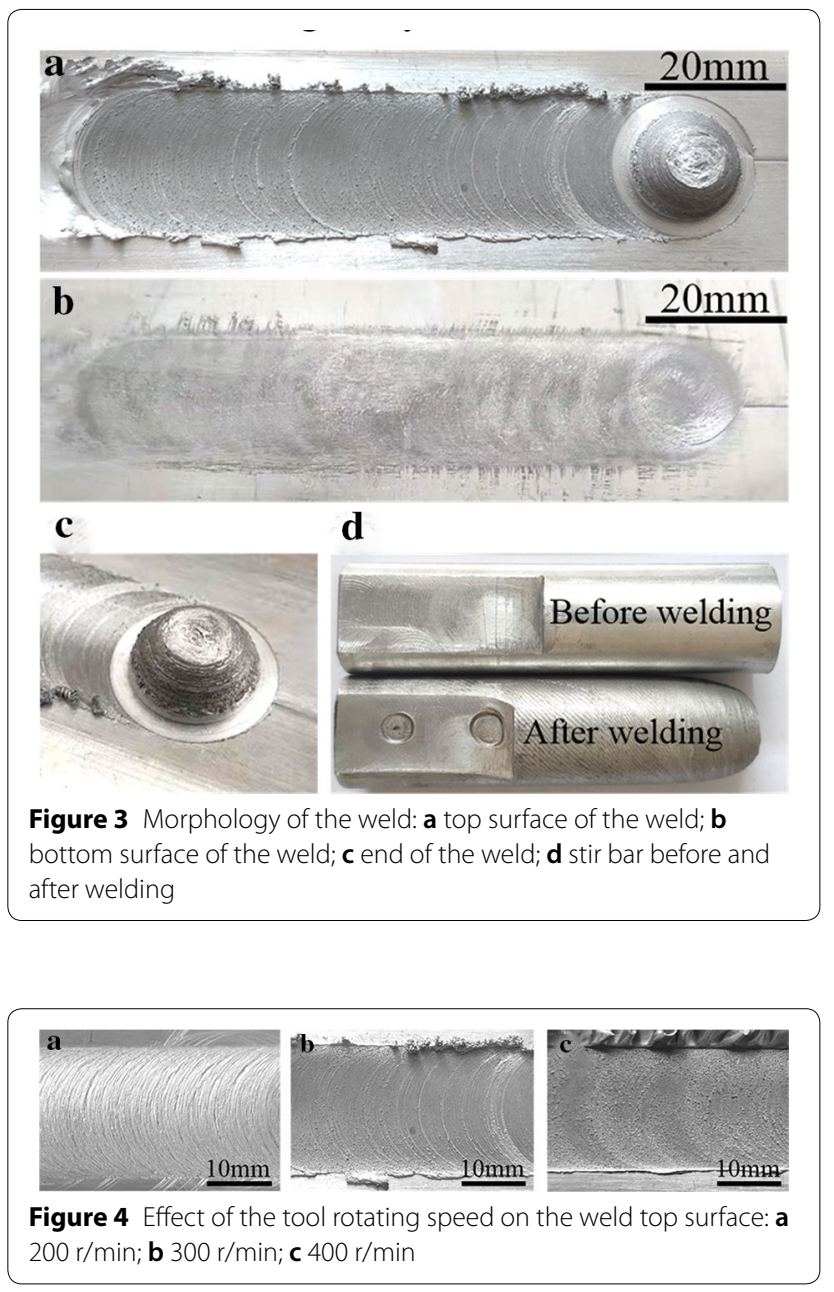

Figure 4 shows the weld top surface quality with respect to the tool rotating speed. The weld top surface quality first raised and then declined as the tool rotating speed increased. At $200 \mathrm{r} / \mathrm{min}$, although the weld has no flash, the surface roughness is not very good. At $300 \mathrm{r} /$ min, a little flash occurred, but the surface roughness is better than that at $200 \mathrm{r} / \mathrm{min}$. When the rotating speed increases to $400 \mathrm{r} / \mathrm{min}$, except for a lot of flashes, the weld surface roughness worsened. Many burrs occurred on the weld surface. This may be caused by the increased welding temperature as the rotating speed increased. Pure aluminum has very high viscosity at elevated temperatures. This gives rise to the burr when the viscoplastic weld material was separated from the holder.

Figure 5 shows the weld macro structures on the transverse cross-section at various tool rotating speeds. They are similar to those in conventional FSW. It also meets the concept of the weld macrostructure in the conventional FSW. Namely, the side where the material flow is according to the welding direction is called the advancing side (AS), and the side where the material flow is opposite 


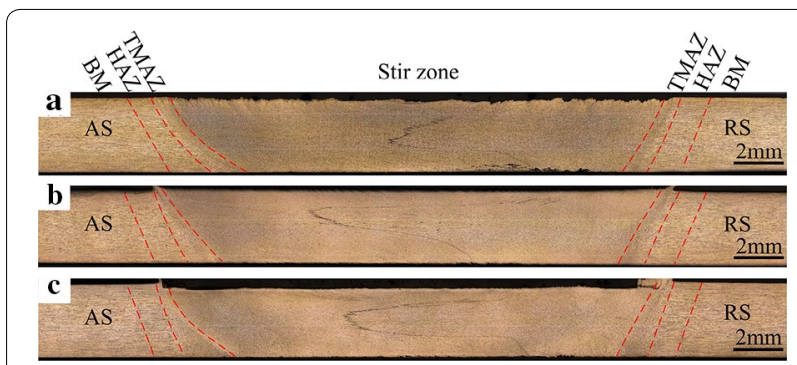

Figure 5 Weld transverse cross-section with respect to the tool rotating speed: a $200 \mathrm{r} / \mathrm{min} ; \mathbf{b} 300 \mathrm{r} / \mathrm{min}$; $400 \mathrm{r} / \mathrm{min}$

to the welding direction is called the retreating side (RS). From the weld center to the two sides BM, there successively exist the stir zone, the thermal-mechanical affected zone (TMAZ), and the heat affected zone (HAZ). In the stir zone, there exists a zigzag line, which was formed by the remain oxides on the original butting surface of the workpieces. The zigzag line has been widely reported in the conventional FSW of pure aluminum and its alloys [22, 23]. It is a common phenomenon and can be removed by careful cleaning of the oxides before welding. The effect of zigzag-line on the joint mechanical properties has been widely studied $[24,25]$. They suggested that it has almost no effect on the joint tensile properties.

Figure 6 shows the typical macrostructure of the vortex material flow. They were obtained from the longitudinal cross-section of the lug boss at $300 \mathrm{r} / \mathrm{min}$ (Figure 6a) and $400 \mathrm{r} / \mathrm{min}$ (Figure 6b). Some common characteristics can be observed through the comparison between Figure 6a and b. Most remarkably, a core metallurgically formed in the axis of the lug boss. This core vertically inserted into the workpiece and nearly reached the bottom. It is reasonable to infer that this core was formed by the vortex material flow. According to the metallographs, an obvious area existed around

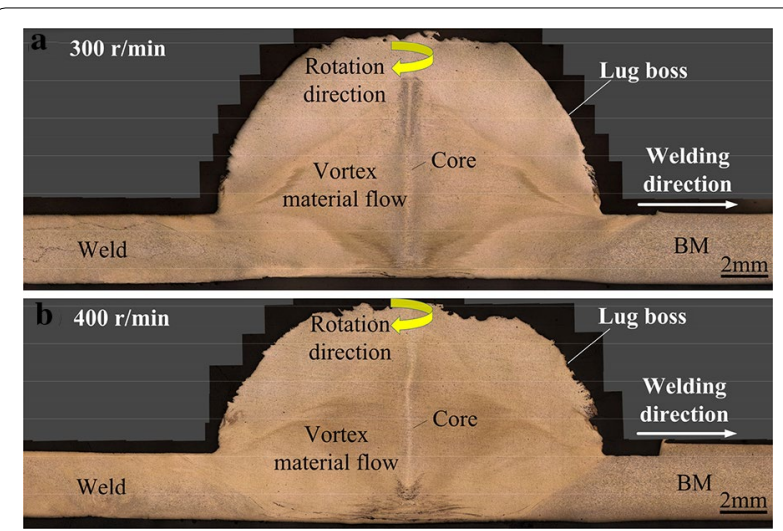

Figure 6 Macrostructure of the vortex material flow: a $300 \mathrm{r} / \mathrm{min}$; b $400 \mathrm{r} / \mathrm{min}$ the core. This is the vortex material flow zone. This zone was firstly formed due to the momentum transfer from the stir bar. Then, the vortex material flow drove the circumjacent material to form the weld. Therefore, the heat generation in the VFSW, no longer like the conventional FSW, does not depend on the friction between the tool and the workpiece, but completely depends on the viscous dissipation due to the internal friction during the material flow. Therefore, the VFSW thoroughly avoids the wear and break of the tool which may occur in conventional FSW. Predictably, this advantage will be more brilliant in welding high-softening-temperature materials.

Figure 7 shows the microhardness maps of the weld transverse cross-section. The microhardness distribution in VFSW is also similar to that in conventional FSW. Namely, the stir zone has the minimum hardness and the hardness distribution in the stir zone is nearly uniform. From the stir zone to the BM, the microhardness gradually increased. However, the hardness in the stir zone varied in nonlinear with respect to the tool rotating speed. At $200 \mathrm{r} / \mathrm{min}$, the average microhardness in the stir zone was about $\sim 31 \mathrm{Hv}$. At $300 \mathrm{r} / \mathrm{min}$, the average microhardness decreased to $\sim 29 \mathrm{Hv}$. However, at $400 \mathrm{r} / \mathrm{min}$, the average microhardness increased to $\sim 33 \mathrm{Hv}$. These microhardness values are equivalent to those in the conventional FSW of pure aluminum [26]. The softening in the stir zone should be attributed to the dynamic recrystallization occurred in the stir zone. Liu et al. [27] clarified that the continuous dynamic recrystallization dominates during the FSW of pure aluminum. Similar to the conventional FSW, the VFSW is also a hot plastic deformation process. Therefore, it is believed that the continuous dynamic recrystallization also dominates during the VFSW of pure aluminum. For the polycrystalline pure aluminum, the microhardness follows the Hall-Petch relationship [28]: $\mathrm{Hv}=H_{0}+k_{H} d^{-1 / 2}$, where $H_{0}$ and $k_{H}$ are positive constants for the specific materials in the microhardness test, $d$ is the grain size. Namely, the smaller is the grain size, the higher is the microhardness. According to this relationship, it can be inferred that the recrystallized grain size obeys the following ranking: $d_{300} \mathrm{r} /$ $\min >d_{200 \mathrm{r} / \mathrm{min}}>d_{400 \mathrm{r} / \mathrm{min}}$, where $d_{200 \mathrm{r} / \mathrm{min}}, d_{300 \mathrm{r} / \mathrm{min} \text {, and }}$

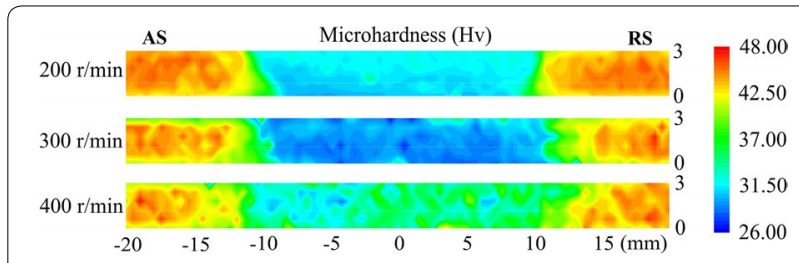

Figure 7 Microhardness map on the weld transverse cross-section 
$d_{400 \mathrm{r} / \mathrm{min}}$ stand for the grain size of the stir zone at tool rotating speed $200 \mathrm{r} / \mathrm{min}, 300 \mathrm{r} / \mathrm{min}$, and $400 \mathrm{r} / \mathrm{min}$, respectively.

The recrystallized grain size can be estimated by the Zener-Holloman parameter $(Z)$ using the following equation [29]:

$$
Z=\dot{\varepsilon} \exp (Q / R T),
$$

and the fitting equation [30]:

$$
d=(a+b \log Z)^{-1},
$$

where $\dot{\varepsilon}$ is the strain rate, $Q$ is the apparent activation energy, $R$ is the gas constant, and $T$ is the deformation temperature. $d$ is the grain size, $a$ and $b$ are fitting constants related to the materials. According to this relationship, the strain rate and the deformation temperature have the opposite effects on recrystallized grain size, i.e., the higher strain rate and lower deformation temperature contribute to smaller grain size; the lower strain rate and higher deformation temperature lead to larger grain size. Generally speaking, the higher rotating speed contributes to a higher strain rate and a higher welding temperature in conventional FSW [31]. Therefore, the strain rate at $300 \mathrm{r} / \mathrm{min}$ may be a little higher than that at $200 \mathrm{r} / \mathrm{min}$, but the welding temperature at $300 \mathrm{r} / \mathrm{min}$ may be much higher than that at $200 \mathrm{r} / \mathrm{min}$. This is why $d_{300 \mathrm{r} / \mathrm{min}}>d_{200}$ $\mathrm{r} / \mathrm{min}$. Similarly, the strain rate at $400 \mathrm{r} / \mathrm{min}$ may be much higher than that at $300 \mathrm{r} / \mathrm{min}$, but the welding temperature at $400 \mathrm{r} / \mathrm{min}$ may be only a little higher than that at $300 \mathrm{r} / \mathrm{min}$. This gives rise to $d_{400 \mathrm{r} / \mathrm{min}}<d_{300 \mathrm{r} / \mathrm{min} \text {. It can }}$ be inferred that both the higher strain rate caused by the higher rotation speed and the lower welding temperature caused by the lower rotation speed lead to smaller grain size. Nevertheless, the higher rotation speed has a better effect on the grain refinement than the lower rotation speed because of $d_{200 \mathrm{r} / \mathrm{min}}>d_{400 \mathrm{r} / \mathrm{min}}$.

Figure 8 shows the microstructures of the weld and the vortex material flow zone. The corresponding misorientation angle distributions are shown in Figure 9. They were obtained on the longitudinal cross-section of the lug boss, as shown in Figure 8a. The statistic grain size and LAB fraction are listed in Table 1. The EBSD IPF map in Figure $8 \mathrm{~b}$ is located in the weld zone. The average grain size is $3.50 \mu \mathrm{m}$. The LAB fraction is only $27.5 \%$. This means that the weld microstructure was fully recrystallized during the welding process. The misorientation angle distribution in Figure 9b also confirmed this result. Figure $8 \mathrm{c}$ and $\mathrm{d}$ show the microstructures at the transition region between the weld zone and the vortex material flow zone. The corresponding misorientation angle distributions are shown in Figure 9c, d. The grain sizes in locations c and d are 3.35 and $3.38 \mu \mathrm{m}$, respectively,

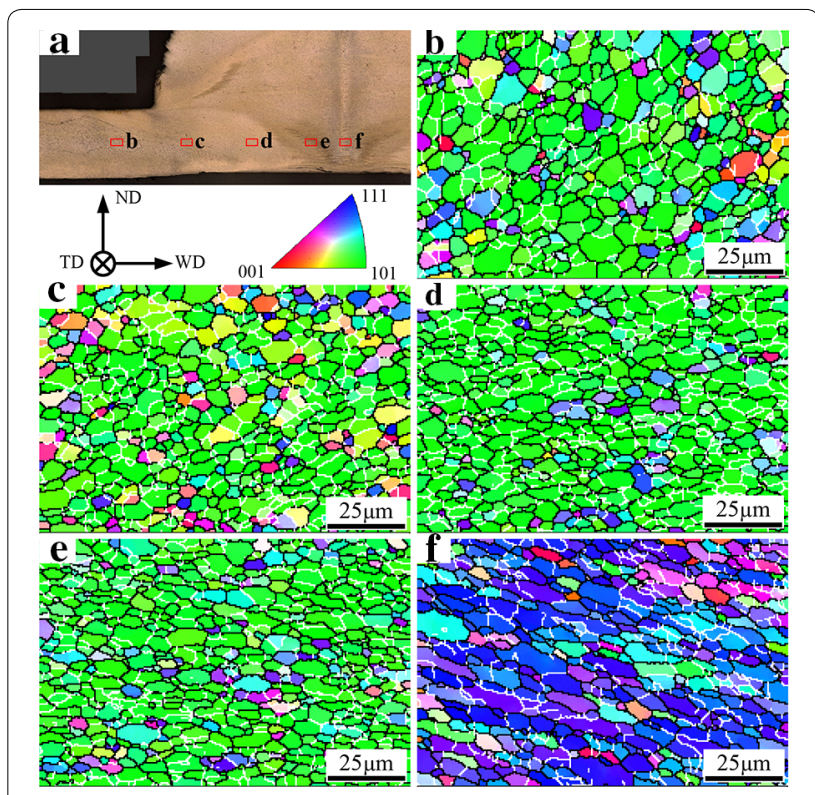

Figure 8 Microstructure of the weld and the vortex material flow zone (300 r/min): a schematic of the measured location; $\mathbf{b}-\mathbf{f}$ EBSD IPF maps corresponding to the locations $\mathbf{b}-\mathbf{f}$ in $\mathbf{a}$
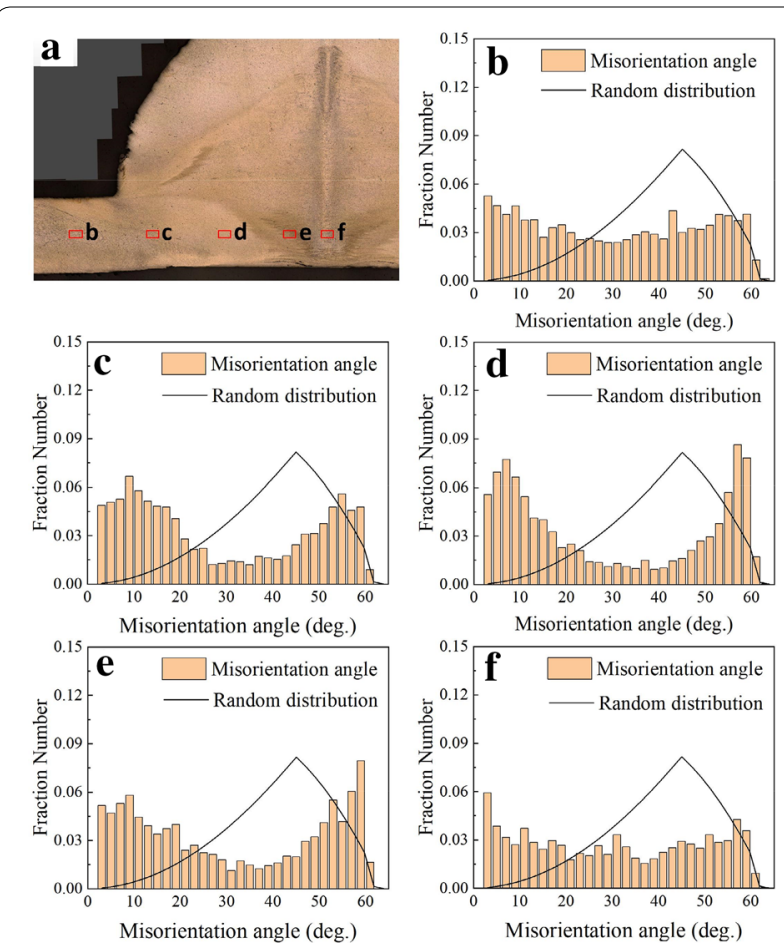

Figure 9 Misorientation angle distributions of the weld and the vortex material flow zone (300 r/min): a schematic of the measured location; b-f Misorientation angle distribution histograms corresponding to the locations $\mathbf{b}-\mathbf{f}$ in $\mathbf{a}$ 
Table 1 Statistic grain size and LAB fraction at the locations in the vortex material flow zone

\begin{tabular}{lccccc}
\hline & b & c & d & e & f \\
\hline Grain size $(\mu \mathrm{m})$ & 3.50 & 3.35 & 3.38 & 3.21 & 3.31 \\
LAB fraction $(\%)$ & 27.5 & 35.3 & 38.5 & 30.9 & 28.2 \\
\hline
\end{tabular}

which are a little smaller than that at the weld zone. The $\mathrm{LAB}$ fractions are $35.3 \%$ and $38.5 \%$, respectively. These are a little higher than that at the weld zone. This indicated that the dynamic recrystallization in this region is not very sufficient. Figures $8 \mathrm{e}$ and $9 \mathrm{e}$ show the microstructures at the vortex material flow zone. The grain size and the LAB fraction are $3.21 \mu \mathrm{m}$ and $30.9 \%$, respectively. Both are lower than those in the transition region. This indicated that the deformation in the vortex material flow zone was more severe. The microstructure at the center of the vortex material flow zone is shown in Figures $8 \mathrm{f}$ and 9 . The grain size and LAB fraction are $3.31 \mu \mathrm{m}$ and $28.2 \%$, respectively, which indicated the dynamic recrystallization in the center of the vortex material flow zone is also sufficient. Generally, the dynamic recrystallization depends on the strain, strain rate, and deformation temperature. As for the vortex material flow, the strain should be large enough for the dynamic recrystallization. Therefore, the grain structure evolution in the vortex material flow zone is mainly controlled by the strain rate and the temperature. The microstructure characteristics show that the temperature and strain rate distributions in the vortex material flow are not uniform. However, the strain rate and temperature distribution in the vortex material flow are difficult to detect directly. They should be investigated using a numerical simulation method in the next study.

In addition, the IPF maps in Figure 8b-e shows that the $<101>$ orientation is parallel to the transverse direction (TD). However, in Figure 8f, the $<111>$ orientation is parallel to the TD. It means that the $<101>$ orientation is parallel to the welding direction (WD). The $<101>$ orientation is the slip direction of the face-centered cubic (FCC) crystal. In the shear deformation, the $<101>$ orientation is usually parallel to the shear direction. This means that the shear direction at the locations b-e is parallel to the TD, but the shear direction at the location $\mathrm{f}$ is parallel to the WD. This indirectly shows that the vortex material flow is an essentially rotational shear deformation process.

Figure 10 shows the grain orientation information in the different locations of the vortex material flow zone. The standard pole figures of simple shear textures in FCC are first given in Figure 10a [32]. Figure 10b shows the shear direction (SD) and the shear plane normal (SPN) at the measured locations. The shear plane at the weld zone is roughly parallel to the weld border on the weld transverse cross-section. From the transition zone to the center of the vortex, the included angle between the shear plane and the horizontal plane gradually decreased. At the center of the vortex material flow zone, the shear plane is parallel to the horizontal plane. This directly indicated that the material flow in the vortex was driven by the momentum transfer from the stir bar. Figure $10 c_{1}-g_{1}$ shows the pole figures at the corresponding locations in Figure 10b. The corresponding IPF maps under the SD and SPN coordinate and the color scattered figures are shown in Figure $10 c_{2}-g_{2}$ and $\mathrm{C}_{3}-\mathrm{g}_{3}$, respectively. At the weld zone, the texture was dominated by the $\mathrm{B} / \overline{\mathrm{B}}\{112\}<110>$ and $\mathrm{C}\{001\}<110>$ simple shear textures. As shown in Figure $10 c_{2-3}$, the red and green area denotes the $\mathrm{B} / \overline{\mathrm{B}}$ components, and the blue area denotes the $\mathrm{C}$ components. At the transition zone and the vortex zone, the texture was only dominated by $\mathrm{B} / \overline{\mathrm{B}}\{112\}<110>$, as shown in Figure $10 \mathrm{~d}_{2}$. ${ }_{3}, \mathrm{e}_{2-3}$ and $\mathrm{f}_{2-3}$. At the center of the vortex material flow zone, the texture was dominated by A/A $\{111\}<110>$ and $B / B\{112\}<110>$. Liu et al. [21] reported that the $\mathrm{A} / \overline{\mathrm{A}}$ texture tends to be developed at a high strain rate, while the $B / \bar{B}$ and $C$ textures tend to be developed at a relatively low strain rate. Therefore, the strain rate in the center of the vortex material flow zone may be higher than that in other zones.

\section{Conclusions}

In summary, a new modification friction stir welding (FSW) process, Vortex-FSW (VFSW), was developed in this study. The tool in VFSW was made by the identical material with the BM. This makes it possible to avoid the tool wear and break. Pure aluminum was welded successfully by the VFSW process in this study. The following conclusions can be drawn:

1 During the VFSW process, the tool material drove the workpiece material to form a vortex material flow beneath the tool due to the momentum transfer. It played the role of the tool in conventional FSW.

2 A lug boss formed at the end of the weld when the tool material was separated from the weld material. The weld top surface and the transverse cross-section were similar to that in conventional FSW.

3 The joint mechanical properties were also equivalent to that in conventional FSW. The microstructure in the weld zone was characterized by fully recrystallized grain. 


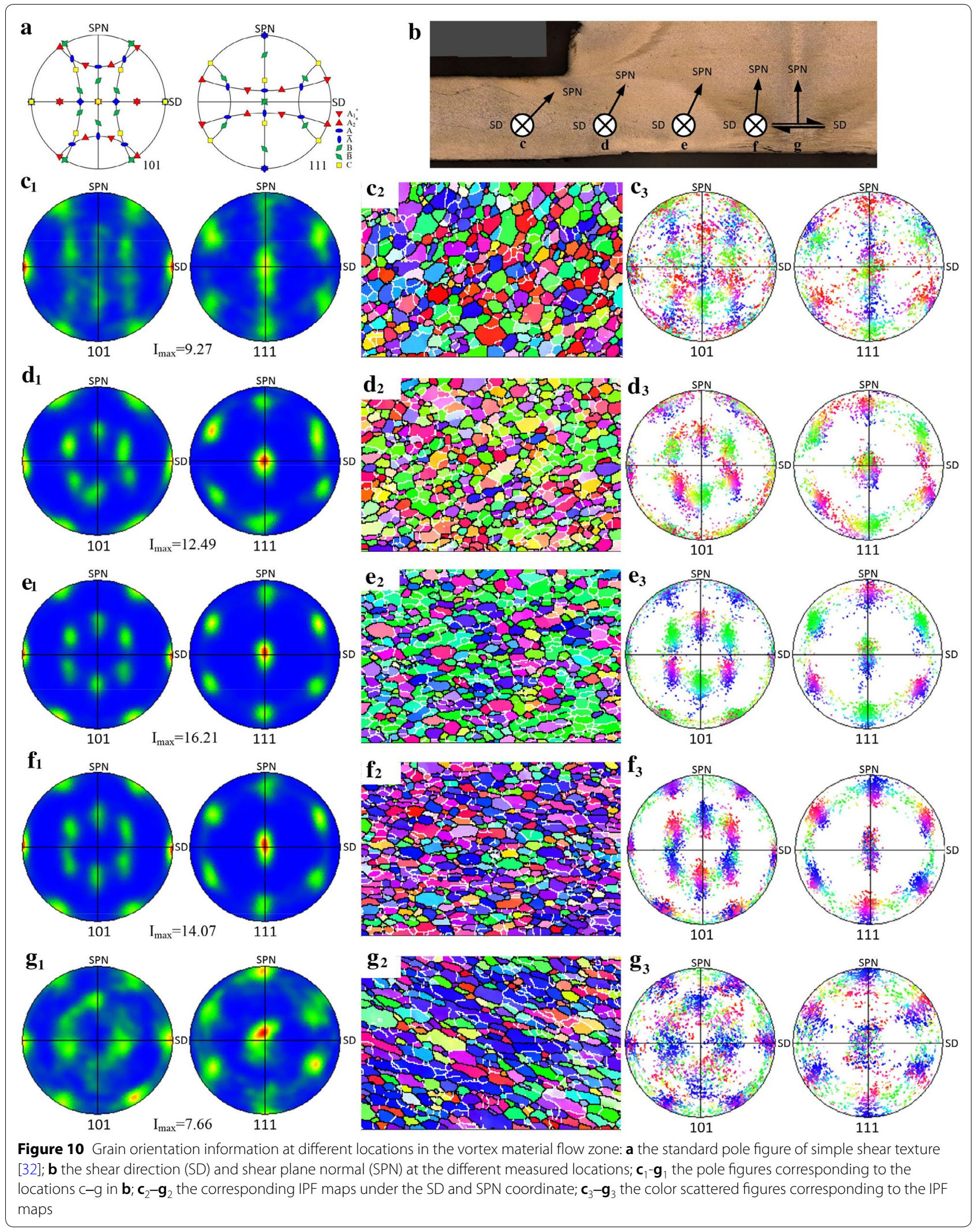


4 The grain structure and texture in the vortex material flow zone verified that the vortex material flow is a rotational shear deformation process. The strain rate and temperature distributions in the vortex are not uniform.

\begin{abstract}
Acknowledgements
The authors sincerely thanks to Professor Chuansong Wu of Shandong University and Yufeng Sun of Zhengzhou University for their critical discussion and reading during manuscript preparation.
\end{abstract}

\section{Authors' contributions}

$\mathrm{XL}, \mathrm{ZS}$ and $\mathrm{HC}$ were in charge of the whole trial; $\mathrm{XL}$ wrote the manuscript; $\mathrm{YZ}$ WL, WG and $Z Y$ assisted with sampling and laboratory analyses. All authors read and approved the final manuscript.

\section{Authors' information}

Xiaochao Liu, born in 1990, is currently an associate professor at Northwestern Polytechnical University, China. He received his PhD degree in Osaka University, Japan, in 2018. He received his master degree in Shandong University, China, in 2015. His current research focuses on friction stir welding of high-softeningtemperature materials.

Yunqian Zhen, born in 1994, He is currently a master candidate at School of Materials Science and Engineering, Northwestern Polytechnical University, China.

Zhikang Shen, born in 1983, is currently an associate professor at Northwestern Polytechnical University, China. He received his PhD degree in Tianjin University, China, in 2015. He received his master degree in Lanzhou University of Science and Technology, China, in 2011. His current research focuses on friction stir spot welding.

Haiyan Chen, born in 1984, is currently an associate professor at Northwestern Polytechnical University, China. He received his PhD degree in Harbin Institute of Technology, China, in 2013. He received his master degree in University of Chinese Academy of Sciences, China, in 2010. His current research focuses on friction stir welding and brazing.

Wenya Li, born in 1976, is currently a professor at Northwestern Polytechnical University, China. He received his Master degree and PhD degree in Xi'an Jiaotong University, China, in 2001 and 2005, respectively. His current research focuses on friction stir welding and cold spraying.

Wei Guo, born in 1985, is currently a postdoc at Northwestern Polytechnical University, China. He received his PhD degree in Harbin Institute of Technology, China, in 2018. He received his master degree in Northeastern University, China in 2014. His current research focuses on brazing.

Zhufeng Yue, born in 1965, is currently a professor at Northwestern Polytechnical University, China. He received his Master degree and PhD degree in Northwestern Polytechnical University, China, in 1991 and 1994, respectively. His current research focuses on reliability of materials and structures.

\section{Funding}

Supported by National Natural Science Foundation of China (Grant Nos. 51905437, 51975479), China Postdoctoral Science Foundation (Grant No. 2019M653726) and Fundamental Research Funds for the Central Universities (Grant No. 3102019QD0407).

\section{Competing interests}

The authors declare no competing financial interests.

\section{Author Details}

1 School of Materials Science and Engineering, Northwestern Polytechnical University, Xi'an 710072, China. ${ }^{2}$ State Key Laboratory of Solidification, Shaanxi Key Laboratory of Friction Welding Technologies, Xi'an 710072, China. ${ }^{3}$ School of Mechanics, Civil Engineering and Architecture, Northwestern Polytechnical University, Xi'an 710072, China.
Received: 6 March 2020 Revised: 21 September 2020 Accepted: 15 October 2020

Published online: 01 December 2020

\section{References}

[1] W Li, A Vairis, M Preuss, et al. Linear and rotary friction welding review. International Materials Reviews, 2016, 61(2): 71-100.

[2] GK Kadhy, C SWu, S Gao. Friction stir based welding and processing technologies-processes, parameters, microstructures and applications: A review. Journal of Materials Science \& Technology, 2018, 34(1): 1-38.

[3] G Chen, S Zhang, Y Zhu, et al. Thermo-mechanical analysis of friction stir welding: A review on recent advances. Acta Metallurgica Sinica (English Letters), 2020, 33(1): 3-12.

[4] B Meyghani, C Wu. Progress in thermomechanical analysis of friction stir welding. Chinese Journal of Mechanical Engineering, 2020, 33:12.

[5] C S Wu, H Su, L Shi. Numerical simulation of heat generation, heat transfer and material flow in friction stir welding. Acta Metallurgica Sinica, 2017, 54(2): 265-277. (in Chinese)

[6] R S Mishra, ZY Ma. Friction stir welding and processing. Materials Science \& Engineering R, 2005, 50(1): 1-78.

[7] Z K Shen, Y Q Ding, A P Gerlich. Advances in friction stir spot welding. Critical Reviews in Solid State and Materials Sciences, 2019, https://doi.org/1 0.1080/10408436.2019.1671799.

[8] R Rai, A De, H K D H Bhadeshia, et al. Review: Friction stir welding tools. Science and Technology of Welding and Joining, 2011, 16(4): 325-342.

[9] X Liu, CWu, G K Padhy. Characterization of plastic deformation and material flow in ultrasonic vibration enhanced friction stir welding. Scripta Materialia, 2015, 102: 95-98

[10] X C Liu, C S Wu. Elimination of tunnel defect in ultrasonic vibration enhanced friction stir welding. Materials \& Design, 2016, 90: 350-358.

[11] M Zhou, Y Morisada, H Fujii. Effect of Ca addition on the microstructure and the mechanical properties of asymmetric double-sided friction stir welded AZ61 magnesium alloy. Journal of Magnesium and Alloys, 2020, 8(1): 91-102.

[12] M Zhou, Y Sun, Y Morisada, et al. Quasi-in-situ investigation into the microstructure and texture evolution of pure magnesium during friction stir welding. Journal of Magnesium and Alloys, 2020, https://doi. org/10.1016/j.jma.2020.05.015.

[13] X Liu, Y Sun, T Nagira, et al. Effect of stacking fault energy on the grain structure evolution of FCC metals during friction Stir Welding. Acta Metallurgica Sinica-English Letters, 2020, 33: 1001-1012.

[14] T Nagira, X C Liu, K Ushioda, et al. Mechanism of grain structure development for pure $\mathrm{Cu}$ and $\mathrm{Cu}-30 \mathrm{Zn}$ with low stacking fault energy during FSW. Science and Technology of Welding and Joining, 2020, 25(8): 669-678.

[15] T Miyazawa, Y Iwamoto, T Maruko, et al. Development of Ir based tool for friction stir welding of high temperature materials. Science and Technology of Welding and Joining, 2011, 16(2): 188-192.

[16] J Wang, J Su, R S Mishra, et al. Tool wear mechanisms in friction stir welding of Ti-6Al-4V alloy. Wear, 2014, 321: 25-32.

[17] P Sahlot, K Jha, G K Dey, et al. Wear-Induced changes in FSW tool pin profile: Effect of process parameters. Metallurgical and Materials Transactions A, 2018, 49(6): 2139-2150.

[18] X C Liu, Y F Sun, Y Morisada, et al. Dynamics of rotational flow in friction stir welding of aluminium alloys. Journal of Materials Processing Technology, 2018, 252:643-651.

[19] X C Liu, Y F Sun, T Nagira, et al. Experimental evaluation of strain and strain rate during rapid cooling friction stir welding of pure copper. Science and Technology of Welding and Joining, 2019, 24(4): 352-359.

[20] X C Liu, Y F Sun, T Nagira, et al. Evaluation of dynamic development of grain structure during friction stir welding of pure copper using a quasi in situ method. Journal of Materials Science \& Technology, 2019, 35(7): 1412-1421.

[21] X C Liu, Y F Sun, T Nagira, et al. Strain rate dependent micro-texture evolution in friction stir welding of copper. Materialia, 2019, 6: 100302.

[22] Y S Sato, H Takauchi, S H C Park, et al. Characteristics of the kissing-bond in friction stir welded Al alloy 1050. Materials Science \& Engineering A, 2005, 405(1): 333-338. 
[23] H J Liu, Y C Chen, J C Feng. Effect of zigzag line on the mechanical properties of friction stir welded joints of an Al-Cu alloy. Scripta Materialia, 2006, 55(3): 231-234.

[24] H Okamura, K Aota, M Sakamoto, et al. Behaviour of oxides during friction stir welding of aluminium alloy and their effect on its mechanical properties. Welding International, 2002, 16(4): 266-275.

[25] Y S Sato, F Yamashita, Y Sugiura, et al. FIB-assisted TEM study of an oxide array in the root of a friction stir welded aluminium alloy. Scripta Materialia, 2003, 50(3): 365-369.

[26] S Mironov, K Inagaki, Y S Sato, et al. Effect of welding temperature on microstructure of friction-stir welded aluminum alloy 1050. Metallurgical and Materials Transactions A, 2015, 46(2): 783-790.

[27] X C Liu, Y F Sun, H Fujii. Clarification of microstructure evolution of aluminum during friction stir welding using liquid $\mathrm{CO}_{2}$ rapid cooling. Materials \& Design, 2017, 129: 151-163.
[28] Y S Sato, M Urata, H Kokawa, et al. Hall-Petch relationship in friction stir welds of equal channel angular-pressed aluminium alloys. Materials Science \& Engineering A, 2003, 354(1): 298-305

[29] C I Chang, C J Lee, J C Huang. Relationship between grain size and Zener-Holloman parameter during friction stir processing in AZ31 Mg alloys. Scripta Materialia, 2004, 51 (6): 509-514.

[30] $\varnothing$ Frigaard, $\varnothing$ Grong, OT Midling. A process model for friction stir welding of age hardening aluminum alloys. Metallurgical and Materials Transactions A, 2001, 32(5): 1189-1200.

[31] G Chen, Q Ma, S Zhang, et al. Computational fluid dynamics simulation of friction stir welding: A comparative study on different frictional boundary conditions. Journal of Materials Science \& Technology, 2018, 34(1): 128-134.

[32] R W Fonda, K E Knipling. Texture development in friction stir welds. Science and Technology of Welding and Joining, 2011, 16(4): 288-294.

\section{Submit your manuscript to a SpringerOpen ${ }^{\circ}$ journal and benefit from:}

- Convenient online submission

- Rigorous peer review

- Open access: articles freely available online

- High visibility within the field

- Retaining the copyright to your article

Submit your next manuscript at springeropen.com 